Mr Dejan Vuletic, kapetan I klase, Institut za strategijska istraživanja

\section{STANDARDI ZA UPRAVLJANJE SIGURNOŠCU PODATAKA}

UDC: 006.4 : 004.6

Rezime:

U radu su analizirani osnovni pojmovi vezani za upravljanje sigumošcu podataka. Ukazano je na potrebu i znacaj standardizacije u oblasti informaciono-komunikacionih tehnologija, narocito prema standardima Medunarodne organizacije za standardizaciju (International Standardization Organization - ISO). U završnom delu rada prikazane su proaktivne i reaktivne aktivnosti u upravljanju sigurnošcu podataka.

Kljucne reci: podaci, standardi, upravljanje sigurnošcu podataka.

\title{
STANDARDS FOR MANAGEMENT DATA SECURITY
}

\section{Summary:}

In this anticle basic notions of management data security are analyzed. We indicated demand and importance of standardization in information-communication technology domain, especially according to International Standardization Organization. In the final part of the article we illustrated both proactive and reactive activities in management data security.

Key words: data, standards, management data security.

\section{Uvod}

Standardi za upravlja nje sigurnošcu podataka se, prema nameni, mogu podeliti na: standarde za sigurnost proizvoda, standarde za sigurnost procesa i standarde sigurnosti sistema [4].

Standardi koji osiguravaju sigurnost proizvoda definišu pravila pod kojima se može izdati sertifikat koji daje punu garanciju da je neki proizvod ili usluga sigurna. Nakon dve decenije razvoja i zajednic kih napora, pre svega Japana, SAD, Kanade, Evropske unije i medunarodne zajednice, usvojen je standard ISO/IEC 15408 (Security Evaluation Criteria).

U podrucju standarda za sigurnost procesa najznacajniji je ISO/IEC (TR) 13335-x Uputstva za upravljanje sigurnošcu infor macione tehnologije (Guidelines for the Management of IT Security GMITS). Taj standard se sastoji od niza tehnickih izveštaja koji služe kao uputstvo za imple mentaciju sistema upravljanja sigurnošcu podataka resursa i sprovodenje postupka samoocenjivanja.

\section{Standardi ISO/IEC}

Medunarodna organizacija za standardizaciju (International Standardization Organization - ISO) i medunarodna elektrotehnic ka komisija (International Electrotechnical Commis sion - IEC) konstituisale su združeni tehnicki komitet (Joint Technical Committee - JTC), 
ciji je zadatak donošenje standarda iz obla sti informaciono-komunikacionih tehnologija. Britanski institut za standarde pripremio je, a ISO i IEC su usvojili medunarodni standard ISO/IEC 17799 cija je najnovija verzija objavlje na 2005. godine. Ocekuje se da ce navedeni standard 2007. godine zameniti standard ISO 27002 [3], a predstavljace skup pravila namenje nih obezbedenju visokog nivoa upravlja nja sigurnošcu podataka (informacija).

Pored standarda ISO/IEC 17799, odnosno ISO 27002, obja vlje ni su ili su u razvoju sle deci, sa aspekta upravlja nja sigurnošcu, znacajni standardi:

- ISO 27001 - Information Security Management System (ISMS) requirements.

Ovaj standard obja vljen je u oktobru 2005. godine, a zasnovan je na britanskom standardu BS 7799-2. Definiše zahteve koje mora da ispuni sistem za upravlja nje sigurnošcu podataka, da bi akreditovana organizacija mogla da ga sertifikuje [2];

- ISO 27004 - Infor mation Se curity Management Metrics and Me asurement.

Ovaj standard je još uvek u razvoju i ocekuje se da ce biti objavljen 2007. godin?. Treba da pomogne organizacija ma u merenju i izveštavanju o efikasnosti njihovih sistema za upravljanje sigurnošcu podataka obuhvacenih postupcima upravlja nja sigurnošcu (definisanih u ISO 27001) i kontrolama (obuhvacenih u ISO 27002);

- ISO 27005 - Information Security Risk Management.

Ocekuje se da ce biti objavljen 2008. ili 2009. godine. Zasnivace se na britanskom standardu BS 7799-3, koji je objavljen u martu 2006. godine. Ovaj standard ce obuhvatati procenu rizika, sprovodenje odgovarajucih kontrola, nadgle danje i ponovnu procenu rizika $u$ toku rada ili periodicno, održavanje i stalno unapredenje sistema kontrole i drugo.

Model sistema upravlja nja sigurnošcu podataka, koji podržava standard ISO/IEC 17799 primenljiv je za organizacije svih tipova i velicina, a može se prila goditi razlicitim geografskim, kulturnim i socijalnim uslovima. Ovaj standard za dovolja va potrebe razlicitih organizacija širom sve ta, osiguravajuci im zajednicki okvir za bavlje nje pitanjima u vezi sa sigurnošcu podataka [4].

Standard ISO/IEC 17799 bavi se proble matikom de finisanja politike sigurnosti i primene opšte dobre prakse upravlja nja sigurnošcu poda taka. Termin ,,politika racunarske sigurnosti“ de finiše se kao direktiva rukovodstva da se formira plan zaštite podataka, utvrde cilje vi i odrede odgovornosti [8]. Taj standard pruža dragocenu pomoc kao pregled visokog nivoa koji menadžmentu kompanije omogucava da sagle da i razume problematiku upravlja nja sigurnošcu podataka u sopstve noj or ganizaciji [4].

Upravljanje sigurnošcu podataka $u$ racunarskim sistemima može se, uslovno, podeliti na dva dela - proaktivno i reaktiv no de lovanje.

Proaktivnim delovanjem se, prvenstve no, one mogucava, ote žava ili sprecava neovlašcenim licima da dodu do sadržine podataka ili dokumenata.

Reaktivnim delovanjem obezbeduje se da sistem povrati osnovne servise (odredene nivoe integriteta, poverljivosti, performansi i drugih kvalitativnih svojstava). 


\section{Proaktivno delovanje}

Najbolji me tod eliminisanja ili ublaža vanja rizika jeste proaktiv no de lovanje koje se obezbeduje višestrukim sferama.

Model ešelonirane višeslojne zaštite podataka realizuje se modelom zaštitnih prstenova (sfera) koji cine:

- sfera fizic ke zaštite (onemogucava fizic ki pristup napadaca);

- tehnicka sfera (sistemi za de tekciju i sprecavanje napada i dr.);

- kadrovska sfera (pravilan izbor kadrova i obezbedenje optimalnih uslova rada);

- or ganizaciona sfera (mere i aktivnosti, nadležnosti i obaveze korisnika i izvršila ca, kao i pristup resursima),

- normativna sfera (zakoni, uputstva, pla novi i druge regulative koje obavezuju i propisuju izvršenje neke radnje i nacin izvršenja te radnje).

Standard ISO 17799 reguliše, sa aspekta proaktivnog delovanja, znacajne mere [1].

U delu „Kontrolisanje pristupa mreži " na vodi se da treba kontrolisati pristup internim i eksternim mrežnim uslugama (servisima).

Delovi „Politika korišcenja mrežnih usluga (servisa)“ i „Ogranicenje pristupa informacijama“ upozoravaju da korisnicima treba obezbediti direktan pristup samo onim uslugama za koje imaju odobrenje za korišcenje. To kontrolisanje je posebno važno kod mrežnog povezivanja sa osetljivim ili kritic nim poslovnim aplikacijama ili sa korisnicima na mestima velikog rizika, npr. javnim ili spoljnim podrucjima koja su izvan kontrole i upravlja nja sigurnošcu u or ganizaciji.
Deo „Politika u pogle du elektronske pošte" reguliše da organizacije treba da projektuju jasnu politiku u pogledu elektronske pošte (zaštitu od sadržaja pridodatih elektronskoj pošti, uputstva kada ne treba koristiti elektronsku poštu i sl.).

Deo „Nadgle danje pristupa i korišcenja sistema" ukazuje na to da siste me treba nadgle dati, ka ko bi se otkrila odstupanja od politike kontrole pristupa i zapisali uoc ljivi dogadaji, da bi se obezbedili dokazi za slucajeve incidenata $u$ pogle du sigurnosti.

Deo „Kriptografske kontrole“ realizuje se s ciljem da se zaštiti poverljivost, verodostojnost ili celovitost informacija. Kriptografske sisteme i postupke treba primenjivati radi zaštite podataka za koje se smatra da su u opa snosti i kojima druge kontrole ne pružaju dovoljnu zaštitu.

Deo „Samozaštita zapisa u organizaciji“" ukazuje na to da važne zapise u nekoj organizaciji treba zaštititi od gublje nja, uništenja i falsifikovanja. Vremenski period i sadržaj podataka koji se cuvaju mogu biti predvideni regulativom. Zapise treba razvrstati u kategorije tipova zapisa, npr. zapise u bazama podataka, zapisnike o transakcijama, zapise o proverama i operativnim procedurama, svaki sa de taljima o periodu cuvanja i tipu medijuma na kojima se oni cuvaju. Sistem za skladištenje podataka treba odabrati tako da se potrebni podaci mogu pretraživati na nacin koji je zakonski i sudski prihvatljiv, npr. da se svi potrebni zapisi mogu izvuci u prihvatljivom roku i formatu. Sistemi za skla dištenje i rad sa podac ima treba da osiguraju ja snu identifikaciju zapisa i njihov statutarni ili regulativni period cuvanja. Sistem mora do- 
zvolja vati odgovarajuce uniš ta vanje zapisa po is te ku tog perioda ako or ganizaciji više nisu potrebni.

Da bi se is punile ove obaveze, unutar organizacije treba preduzeti sle dece korake:

- izdati uputstvo o cuvanju, skla dištenju, postupanju i odbacivanju zapisa i informacija;

- izraditi nacrt - termin plana za cuvanje, kojim se identifikuju najvažniji tipovi zapisa i period u kojem ih treba sacuvati;

- održavati inventarski popis izvora kljuc nih informacija;

- uvesti odgovarajuce kontrole radi zaštite najvažnijih zapisa i informacija od gublje nja, uniš tenja i falsifikovanja.

$\mathrm{U}$ novije vreme posebno znacajan segment zaštite podataka predstavljaju odredena hardverska i softverska rešenja za de tekciju i sprecavanje napada. Proizvodaci racunarske opreme sve više isticu mere sigurnosti. Tako je Bil Gejts istakao da ce prioritet u razvoju Mic rosoft proizvoda ubuduce imati zaštita [7].

\section{Reaktivno de lovanje}

Kada pored proaktivnog delovanja dode do incidenta, organizacije moraju biti spremne da se suprotstave brzo i efikasno, da bi se minimizirao negativan uticaj i prikupili neophodni podaci koji bi doveli do pocinioca kriminalne radnje.

Ne ula zeci u uzroke incidenta, nakon nje ga sle decih šest koraka znatno ce pomoci da se upravlja brzo i efikasno [6]:

- zaštita života i bezbednosti ljudi;

- lokalizovanje oštecenja;

- procena oštecenja;

- utvr divanje uzroka oš te cenja;
- oporavak oš tecenja, i

- razmatranje reakcije (odgovora) i ažuriranje politike.

Mnoge kompanije, organizacije i vladine agencije imaju implementirane kapacitete za odgovore na incident (incident management), fokusirajuci se, pre svega, na sle dece aspekte [5]:

- efikasan odgovor (obuhvata: pripremu, identifikovanje, zadrža vanje, eliminisanje, oporavak i pracenje);

- centralizaciju (za izveštavanje, suprostavlja nje incidentu i sl.),

- pobolj šanje sve sti korisnika.

Kada se napad desi, ili sistem bude kompromitovan, veoma je važno prikupiti podatke (dokaze) o tome šta se de silo. U odredenim granicama racunari i ostali mrežni uredaji (npr. sistemi za detekciju upada) sposobni su da zabeleže aktivnosti koje su se dogodile u njihovim granicama ili prošli kroz njih. Ta evidencija je neophodan ele ment procesuiranja odgovornih lica.

Zavisno od procenjenih rizika, nužno je da svaka organizacija sacini ,plan upravljanja kontinuitetom poslovanja“. Upravljanje kontinuitetom poslovanja treba da obuhvati kontrole za identifikovanje i smanjivanje rizika, za ogranicavanje posle dica incidenata i da osigura da se važne operacije pravovremeno ponovo zapocnu. Postupak upravlja nja kontinuitetom poslovanja treba uvesti kako bi se smanjile posle dice štetnih dogadaja na prihvatljiv nivo kombinovanjem kontrola za prevenciju i za oporavak. Usled razlicitih promena rizika, loših procena ili drugih faktora, planove za kontinuitet poslovanja treba održavati kroz redovno preispitivanje i ažuriranje, kako bi se osigurala njihova 
efikasnost. Kada je sacinjen takav plan, od strategijskog znacaja, neophodno ga je primenjivati u praksi [1].

\section{Zakljucak}

Baze podataka veoma su ranjive i izložene ozbiljnim potencijalnim opasnostima. Apsolutna sigurnost podataka nije moguca. U skladu sa potencijalnim opasnostima moguce je jedino upravlja ti sigurnošcu podataka, a rizike svoditi na minimum.

Upravlja nje sigurnošcu podataka otežavaju stalne promene rizika s obzirom na to da se nijedan incident ne može predstaviti kao tipican. To je konstantan proces koji zahteva saradnju svakog dela i cla na or ga nizacije.

Sve je veci broj organizacija u kojima, pored vodeceg službe nika bezbednosti (Chief Security Officer - CSO), post?ji, kao za sebna funkcija, vodeci službenik informacione bezbednosti (Chief Information Security Officer - CISO). Vodeci službenik informacione bezbednosti pripada top-menadžmentu organizacije i bavi se razradom i realizacijom politike bezbednosti. Pored vodeceg slu- žbenika informacione bezbednosti, sve je cešca i funkcija menadžera službe IB (Business Information Security Officer BISO), koji se ba vi praktic nom realizacijom politike bezbednosti na nivou neke organizacione celine (npr. plansko-ekonomskog, marketinga ili odeljenja IT).

Upravljanje sigurnošcu podataka prerasta u zasebnu delatnost sa široko razgranatom le pezom profesija i sa sve vecim brojem ljudi koji ce profesionalno raditi na tim pitanjima.

Literatura:

[1] ISO/IEC 17799 Information technology - Code of practice or information security management, 2005.

[2] ISO 27001 - Information Security Management System (ISMS) requirements, http://www.iso27001/security.com/html/iso27001.html

[3] ISO 27002, http://www.iso27001/security.com/html/ iso $27002 . \mathrm{html}$

[4] Kukrika, M.: Upravljanje sigurnošcu informacija, INFOhomePress, Beograd, 2002

[5] Schweitzer, D.: Incident Response: Computer Forensics Toolkit, Wiley Publishing, Indianapolis, 2003.

[6] Security Risk Management Guide, Microsoft Corporation, 2004 (ažurirana marta 2006)

http://www.microsoft.com/technet/security/topics/complian ceandpolicies/secrisk/

[7] Shinder, D.: Scene of the Cybercrime: Computer Forensics Handbook, Syngress Publishing, Inc., Rockland (USA), 2002.

[8] Swanson, M.; Guttman, B.: Generally Accepted Principles and Practices for Securing Information Technology Systems, National Institute of Standards and Technology, Gaithersburg, 1996. 